\title{
AMBIENTES PROTEGIDOS E SUBSTRATOS COM DOSES DE COMPOSTO ORGÂNICO COMERCIAL E SOLO NA FORMAÇÃO DE MUDAS DE JATOBAZEIRO EM AQUIDAUANA - MS
}

\author{
LÉIA C. R. DOS SANTOS ${ }^{1}$, EDILSON COSTA ${ }^{2}$, PAULO A. M. LEAL ${ }^{3}$, \\ EVANDRO M. V. NARDELLI ${ }^{4}$, GUILHERME S. A. DE SOUZA $^{5}$
}

\begin{abstract}
RESUMO: O Cerrado brasileiro possui inúmeras espécies frutíferas com potencial econômico para exploração em cultivo comercial. Neste contexto, desenvolveu-se um experimento com mudas de jatobá-do-cerrado na Universidade Estadual de Mato Grosso do Sul, em Aquidauana - MS, de 29-outubro-2009 a 25-fevereiro-2010, em estufa agrícola coberta com filme de polietileno de $150 \mu \mathrm{m}$, difusor de luz, possuindo tela termorrefletora de $50 \%$ sob o filme e fechamentos laterais e frontais com tela de monofilamento, malha para $50 \%$ de sombreamento e viveiro com tela preta de monofilamento para sombreamento de $50 \%$, fechamento em $45^{\circ}$. Nesses ambientes, as mudas foram formadas em vasos plásticos de 5,0 L, preenchidos com 100\% de solo, $100 \%$ de composto orgânico e as doses de $10 ; 20 ; 30 ; 40 ; 50 ; 60 ; 70 ; 80$ e 90 de composto orgânico adicionadas ao solo. Utilizou-se um delineamento inteiramente casualizado, em esquema de parcelas subdivididas, com cinco repetições. Em ambos os ambientes de cultivo, as plântulas emergiram mais rapidamente, com maior crescimento e acúmulo de biomassa em substrato sem adição de composto orgânico. As plântulas do substrato sem composto orgânico desenvolveram-se melhor na estufa agrícola. As mudas do jatobá-do-cerrado não apresentaram resposta positiva em relação ao aumento das doses do composto orgânico. $\mathrm{O}$ composto orgânico utilizado aumentou o pH dos substratos, apresentou excesso de certos nutrientes e não contribuiu para um crescimento efetivo das mudas.
\end{abstract}

PALAVRAS-CHAVE: Hymenaea stigonocarpa, fruteiras do cerrado, propagação.

\section{SUBSTRATES WITH ORGANIC COMPOUND AND SOIL FOR JATOBAZEIRO-DO- CERRADO SEEDLINGS UNDER PROTECTED CULTIVATION}

\begin{abstract}
The Brazilian Cerrado has numerous fruit species with economic potential for exploitation in commercial cultivation. In this context an experiment was developed with jatobá-docerrado seedlings at the State University of Mato Grosso do Sul / Aquidauana-MS, from October $29^{\text {th }}, 2009$ to February $25^{\text {th }}, 2010$, in a greenhouse covered with polyethylene film of $150 \mu \mathrm{m}$, light diffuser, with thermal reflective screen of $50 \%$ of shading under film, front and side with monofilament screen of $50 \%$ of shading and the nursery with black monofilament screen of $50 \%$ of shading and closing of 45 degrees. In these environments the plants were grown in plastic pots of $5.0 \mathrm{~L}$ filled with $100 \%$ of soil, $100 \%$ of organic compound and levels of $10,20,30,40,50,60,70$, 80 and 90 of organic compound added to the soil. The experiment was carried out in a completely randomized split-plot scheme with five replications. In both environments, plants have emerged more rapidly, higher growth and more biomass accumulation in the substrate without addition of organic compound. In this substrate the plants developed better in the greenhouse. The seedlings did not show positive response at the organic compost levels. The organic compound used increased the $\mathrm{pH}$ of the substrates, showed excess of certain nutrients and did not contribute to an effective seedling growth.
\end{abstract}

KEYWORDS: Hymenaea stigonocarpa, cerrado fruits, propagation.

\footnotetext{
${ }^{1}$ Mestre, Programa de Pós-Graduação em Agronomia (Produção Vegetal), Universidade Estadual de Mato Grosso do Sul - UEMS, Unidade Universitária de Aquidauana - MS, leiasantos_agro@yahoo.com.br. Bolsista CAPES

${ }^{2}$ Prof. Dr., UEMS, Aquidauana - MS, mestrine@uems.br.

${ }^{3}$ Prof. Titular; FEAGRI/UNICAMP, Campinas - SP, pamleal@ feagri.unicamp.br

${ }^{4}$ Bolsista PIBIC/UEMS, Aquidauana - MS, evandro_nardelli@hotmail.com

${ }^{5}$ Acadêmico, UEMS, Aquidauana - MS, guilhermesouza_14@hotmail.com.

Recebido pelo Conselho Editorial em: 9-11-2010

Aprovado pelo Conselho Editorial em: 3-3-2011
} 


\section{INTRODUÇÃO}

O Jatobá-do-cerrado (Hymenaea stigonocarpa Mart.) é uma importante fruteira do cerrado brasileiro. MATUDA \& MARIA NETO (2005) relatam que seus frutos possuem várias utilidades, das quais FARIA et al. (2006) destacam os alimentares, medicinais e artesanais. Contudo, a exploração desta fruteira é realizada de forma extrativista. VIEIRA et al. (2008) ressaltam que esta espécie possui alto valor econômico pela sua madeira de qualidade, resinas e frutos comestíveis com casca rica em tanino, o que resulta num aumento da procura dessa espécie para plantios comerciais.

A utilização de ambientes protegidos na formação de mudas frutíferas é pré-requisito fundamental, pois permite maior controle fitossanitário, proteção contra intempéries climáticas, produção em qualquer época do ano e uniformidade do plantel. Aliado ao ambiente protegido, o uso de substratos e de recipientes adequados permite a obtenção de mudas vigorosas (REISSER JÚNIOR et al., 2008). O substrato possui a função de proporcionar condições adequadas ao desenvolvimento radicular e sustentação às plântulas, sendo que substratos obtidos próximos da sua utilização apresentam uma redução dos custos de produção das mudas.

CARVALHO (2007) destaca que, na produção de mudas de jatobá (Hymenaea stigonocarpa Mart), deve-se semear uma semente em sacos de polietileno com dimensões mínimas de $22 \mathrm{~cm}$ de altura e $10 \mathrm{~cm}$ de diâmetro, ou em tubetes de $19 \mathrm{~cm}$ de altura e $500 \mathrm{~cm}^{3}$. Geralmente, as mudas estão prontas para ir ao campo aos 3 meses após a semeadura ou com $30 \mathrm{~cm}$ de altura (MELO \& MENDES, 2005).

De acordo com SCREMIN-DIAS (2006), a grande maioria da vegetação nativa está sendo desmatada e substituída por atividades agropastoris e madeireiras, o que resulta em grandes perdas de biomas. Ao contrário, se forem utilizadas de forma sustentável, as plantas nativas, principalmente as frutíferas, podem ser geradoras de renda para uma região. A espécie Hymenaea spp., na região de Aquidauana-MS, pode tornar-se uma alternativa de renda para a população local, junto com o pequi (Caryocar brasiliense) e a guavira (Campomanesia sp.), as quais são espécies muito adaptadas e conhecidas na região. Além do consumo humano, a espécie em questão proporciona conforto térmico aos animais da pecuária pantaneira.

Este trabalho teve como objetivo avaliar o efeito de dois ambientes protegidos e de diferentes composições de substratos com doses de composto orgânico comercial, na emergência e no crescimento de mudas de jatobá-do-cerrado (Hymenaea stigonocarpa Mart.).

\section{MATERIAL E MÉTODOS}

O experimento foi conduzido na Unidade Universitária de Aquidauana, Universidade Estadual de Mato Grosso do Sul, no período de 29 de outubro de 2009 a 25 de fevereiro de 2010 (altitude de $174 \mathrm{~m}$, longitude de $55,67^{\circ} \mathrm{S}$ e latitude de $20,45^{\circ} \mathrm{W}$ ).

Foram utilizados dois ambientes protegidos: (A1) estufa agrícola em arco de estrutura em aço galvanizado (6,40 m de largura x 18,00 m de comprimento x 4,00 m de altura), com abertura zenital na cumeeira, coberta com filme de polietileno de $150 \mu \mathrm{m}$ e difusor de luz, com tela termorrefletora aluminizada (Aluminet ${ }^{\circledR}$ ) de $50 \%$ de sombreamento sob o filme e com fechamentos laterais e frontais com tela preta de monofilamento $\left(\right.$ Sombrite $^{\circledR}$ ), malha para $50 \%$ de sombra, e (A2) telado agrícola de estrutura em aço galvanizado $(6,40 \mathrm{~m}$ de largura $\mathrm{x} 18,00 \mathrm{~m}$ de comprimento $\mathrm{x} 3,50 \mathrm{~m}$ de altura), com fechamentos em $45^{\circ}$ de inclinação de tela preta de monofilamento (Sombrite ${ }^{\circledR}$ ), malha de $50 \%$ de sombreamento.

O ambiente externo regional, de acordo com a classificação de Köeppen é Aw, é definido como região que apresenta clima tropical úmido e com temperatura média anual de $29^{\circ} \mathrm{C}$.

No interior dos ambientes protegidos, as mudas foram formadas em vasos plásticos com capacidade de 5,0 litros, preenchidos com (S1) 100\% de solo; (S2) 90\% de solo e 10\% de composto 
orgânico; (S3) 80\% de solo e 20\% de composto orgânico; (S4) 70\% de solo e 30\% de composto orgânico; (S5) $60 \%$ de solo e $40 \%$ de composto orgânico; (S6) 50\% de solo e 50\% de composto orgânico; (S7) 40\% de solo e 60\% de composto orgânico; (S8) 30\% de solo e 70\% de composto orgânico; (S9) 20\% de solo e 80\% de composto orgânico; (S10) 10\% de solo e 90\% de composto orgânico; (S11) 100\% de composto orgânico. Não foi realizada adubação mineral nos substratos avaliados.

O delineamento foi o inteiramente casualizado, em esquema de parcelas subdivididas (splitplot), com cinco repetições de duas plantas por repetição. As parcelas principais foram os ambientes de cultivo (A), e as subparcelas, as composições de substratos (S).

Utilizou-se o solo, classificado como Argissolo Vermelho-Amarelo, retirado na camada de 10 a $40 \mathrm{~cm}$, e o composto orgânico Organosuper ${ }^{\circledR}$ (Tabela 1).

Os frutos de jatobazeiro foram coletados na região de Aquidauana, sendo posteriormente quebrados, e as sementes, imersas em água por aproximadamente 4,0 horas para melhor retirada da polpa. As sementes foram selecionadas com peso entre 3,5 e 4,5 g, com objetivo de uniformizar a germinação. Foi realizado o processo de quebra de dormência com imersão em água por 24 horas (MOREIRA et al., 2005), e depois a escarificação com lixa d'água n⿳ํㅜ 120 na região do hilo.

TABELA 1. Análise dos substratos utilizados no experimento. Chemical analyses of the substrates used in the experiment.

\begin{tabular}{|c|c|c|c|c|c|c|c|c|c|c|c|c|c|}
\hline Subst. & $\begin{array}{c}\mathrm{pH} \\
\left(\mathrm{CaCl}_{2}\right)\end{array}$ & $\mathrm{Ca}$ & $\mathrm{Mg}$ & $\mathrm{K}$ & $\mathrm{C}$ & MO & $\mathrm{P}$ & $\mathrm{Fe}$ & $\mathrm{Mn}$ & $\mathrm{Cu}$ & $\mathrm{Zn}$ & B & V \\
\hline$* *$ & & \multicolumn{3}{|c|}{$\mathrm{Cmol}_{\mathrm{c}} \mathrm{dm}^{-3}$} & \multicolumn{2}{|c|}{$\mathrm{g} \mathrm{dm}^{-3}$} & \multicolumn{6}{|c|}{$\mathrm{mg} \mathrm{dm}^{-3}$} & $\%$ \\
\hline S1 & 5,30 & 2,52 & 0,70 & 0,12 & 7,82 & 13,45 & 10,95 & 9,06 & 51,85 & 0,06 & 2,32 & 0,91 & $4,2054,9$ \\
\hline $\mathrm{S} 2$ & 6,50 & 4,68 & 2,52 & 0,50 & 19,38 & 33,33 & 293,50 & 43,63 & 162,29 & 0,77 & 28 & 1, & $306,0079,1$ \\
\hline S3 & 6,70 & 6,14 & 4,22 & 0,94 & 32,98 & 56,7 & 499,80 & 86,29 & 174,36 & 1,39 & 31,17 & 1, & $528,0085,7$ \\
\hline $\mathrm{S} 4$ & 6,60 & 6,89 & 6,60 & 1,38 & 52,70 & 90,64 & 460,80 & 124,30 & 189,17 & 1,97 & 31, & 2,87 & $852,0089,5$ \\
\hline S5 & 6,90 & & 5,63 & 1,0 & & & & & & & & & $726,0090,5$ \\
\hline S6 & 6,70 & & 8,20 & 1,8 & & 133 & & 142 & & 2 & 32 , & 4,19 & 091,5 \\
\hline S7 & 6,70 & & 10,67 & 3, & & & & & & 3, & 26 & 11 , & 93,5 \\
\hline S8 & 6,70 & & 10 & 3,6 & & & & & & & & & 093,3 \\
\hline S9 & 6,50 & & 11,82 & 3,92 & 128,76 & & & & & 3,6 & 26,18 & 12,32 & $3.030,0092,7$ \\
\hline $\mathrm{S} 10$ & 6,70 & 14,23 & 11,87 & 3,80 & 118,62 & 204,03 & 684,80 & 126,95 & 157,15 & 4,14 & 26,22 & 14,95 & $2.235,0093,5$ \\
\hline S11 & 6,70 & 14,87 & 11,91 & 3,92 & 139,78 & 240,42 & 704,80 & 118,72 & 147,87 & 4,02 & 26,19 & 15,87 & $3.090,0093,7$ \\
\hline
\end{tabular}

* Fonte: Laboratório de análises: SOLANÁLISE. Extrator Melich : K - P - Fe - Mn - Cu e Zn; Extrator KCl: Ca - Mg - Al; Extrator HCl 0,05N: B; Extrator Fosfato de Cálcio: S. ** (S1) 100\% de solo; (S2) 90\% de solo e 10\% de composto orgânico; (S3) 80\% de solo e 20\% de composto orgânico; (S4) 70\% de solo e 30\% de composto orgânico; (S5) 60\% de solo e 40\% de composto orgânico; (S6) $50 \%$ de solo e $50 \%$ de composto orgânico; (S7) 40\% de solo e 60\% de composto orgânico; (S8) 30\% de solo e 70\% de composto orgânico; (S9) 20\% de solo e 80\% de composto orgânico; (S10) 10\% de solo e 90\% de composto orgânico; (S11) 100\% de composto orgânico.

Colocaram-se duas sementes por vaso no dia 29-10-2009 e realizou-se o desbaste quando as plântulas estavam com duas folhas definitivas. As mudas foram irrigadas com rega manual.

Foi realizada a análise do índice de velocidade de emergência (IVE), com observação das plântulas emergidas diariamente, no período de 11 a 19 de novembro, sendo que uma semente foi considerada emergida quando seus cotilédones estavam acima do nível do substrato.

Foram mensuradas diariamente as temperaturas de bulbo seco e bulbo úmido $\left(\mathrm{T},{ }^{\circ} \mathrm{C}\right)$, às $9 ; 12$ e 15h, em cada ambiente de cultivo e no ambiente externo. Posteriormente, foi determinada a umidade relativa com auxílio do software Psychrometric Function Demo (Tabela 2).

Foram realizadas medidas da altura de plantas (AP), iniciando-se aos 32 dias após a semeadura (DAS), e depois aos 47; 62; 77; 92; 107 e 120 DAS. Para comparar a variável altura em função do tempo, foi utilizada a análise de regressão. 
TABELA 2. Temperatura do ar $\left(\mathrm{T},{ }^{\circ} \mathrm{C}\right)$ e umidade relativa (UR, \%) média do ar nos horários das 9 ; 12 e $15 \mathrm{~h}$ para cada ambiente (A) de cultivo, durante o período do experimento. Aquidauana - MS, 2009-2010. Air Temperature (T, $\left.{ }^{\mathbf{0}} \mathbf{C}\right)$ and relative humidity (RH, $\%$ ) at 9 AM, 12 PM, and 3 PM for each environment (A) during the experiment periods. Aquidauana-MS, 2009-2010.

\begin{tabular}{ccccccc}
\hline \multicolumn{7}{c}{$\mathrm{T}\left({ }^{\circ} \mathrm{C}\right)$} \\
\hline Meses & $9 \mathrm{~h}$ & $12 \mathrm{~h}$ & $15 \mathrm{~h}$ & $9 \mathrm{~h}$ & $12 \mathrm{~h}$ & $15 \mathrm{~h}$ \\
\hline \multicolumn{7}{c}{$\mathbf{A 1}=$ Estufa agrícola } \\
\hline outubro & 29,33 & 34,97 & 37,00 & 62,54 & 45,44 & 37,72 \\
novembro & 30,38 & 33,46 & 34,32 & 66,97 & 59,39 & 59,73 \\
dezembro & 28,37 & 31,20 & 32,39 & 76,11 & 67,20 & 64,12 \\
janeiro & 28,94 & 31,84 & 31,71 & 75,62 & 65,38 & 65,52 \\
fevereiro & 28,95 & 32,95 & 33,91 & 74,96 & 62,48 & 58,64 \\
\hline \multicolumn{7}{c}{$\mathbf{A 2}=$ Viveiro com sombrite ${ }^{\circledR}$} \\
\hline outubro & 29,67 & 34,37 & 37,00 & 64,62 & 54,31 & 53,36 \\
novembro & 30,24 & 33,71 & 34,16 & 69,08 & 58,75 & 58,80 \\
dezembro & 28,44 & 31,16 & 31,70 & 76,84 & 68,89 & 67,60 \\
janeiro & 28,57 & 31,08 & 30,95 & 77,74 & 70,22 & 69,08 \\
fevereiro & 28,61 & 32,56 & 33,27 & 77,12 & 68,19 & 62,33 \\
\hline \multicolumn{7}{c}{ Ambiente externo } \\
\hline outubro & 28,83 & 33,87 & 36,00 & 63,96 & 48,82 & 41,08 \\
novembro & 30,36 & 34,05 & 34,52 & 68,79 & 60,97 & 59,79 \\
dezembro & 28,31 & 30,90 & 32,33 & 79,48 & 72,90 & 67,14 \\
janeiro & 28,75 & 31,32 & 31,40 & 78,41 & 69,33 & 69,23 \\
fevereiro & 28,92 & 32,28 & 33,49 & 77,49 & 67,00 & 63,01 \\
\hline
\end{tabular}

Aos 120 DAS, foram medidas a massa da matéria seca da parte aérea (MSA) e do sistema radicular (MSR). Assim, somaram-se a MSA e a MSR para a obtenção da matéria seca total (MST). Determinaram-se, também, o diâmetro do colo (DC) das plantas e o índice de qualidade de Dickson (IQD) (DICKSON et al., 1960):

$$
I \mathrm{QD}=\frac{\mathrm{MST}(\mathrm{g})}{\frac{\mathrm{AP}(\mathrm{cm})}{\mathrm{DC}(\mathrm{mm})}+\frac{\mathrm{MSA}(\mathrm{g})}{\operatorname{MSR}(\mathrm{g})}}
$$

em que,

IQD - índice de qualidade de Dickson, adimensional;

MST - matéria seca total, g;

AP - altura de plantas, $\mathrm{cm}$; DC = diâmetro do colo, $\mathrm{mm}$;

MSA - matéria seca da parte aérea, g, e

MSR - massa seca do sistema radicular, g.

Os dados foram submetidos à análise de variância, pelo teste $\mathrm{F}$, a $5 \%$ de probabilidade, e quando significativas, as médias foram comparadas pelo teste de Tukey, a 5\% de probabilidade, utilizando o software Estat (1994).

\section{RESULTADOS E DISCUSSÃO}

As emergências das plântulas de jatobazeiro iniciaram aos 13 dias após a semeadura (DAS) na estufa plástica e aos 15 dias após a semeadura (DAS) no telado, a qual pode ser considerada como uma rápida emergência das plântulas. No entanto, CARVALHO FILHO et al. (2003), utilizando mudas de Hymenaea courbaril L., verificaram que a emergência das sementes mostrou-se lenta, iniciando-se aos 20 DAS. MELO \& MENDES (2005) e RAMOS et al. (2003) 
pesquisaram a espécie Hymenaea Stigonocarpa Mart. Ex. Hayne e verificaram que a germinação ocorreu aos 30 DAS. Provavelmente, as altas temperaturas do ar (Tabela 2) observadas nos ambientes, durante o período do experimento, contribuíram para acelerar o processo de emergência das plântulas de jatobazeiro.

Nos interiores da estufa agrícola (A1) e do telado (A2), as plântulas do substrato com 100\% de solo apresentaram maior índice de velocidade de emergência (IVE) que as dos demais substratos, com índices de 1,02 e 0,89, respectivamente; no entanto, no telado, este índice não diferiu do substrato com 70\% de solo (S4) (Tabela 3). Por ser uma espécie adaptada às condições climáticas do cerrado, onde, na maior parte do ano, ocorrem temperaturas elevadas (Tabela 2) e os solos são ácidos (Tabela 1), as plântulas do jatobazeiro tiveram melhores condições iniciais e emitiram mais rapidamente suas radículas no substrato $\mathrm{S} 1$.

Aliado às condições de ambiente e solo, e segundo SALAMONI (2004), que destaca que as sementes de courbaril apresentam elevado tecido de reserva, o que propicia menor absorção inicial de nutrientes e adaptabilidade em solos com baixa fertilidade (LORENZI, 2000), pode-se fazer uma analogia com as sementes da espécie stgnocarpa, a qual apresentou melhores resultados de IVE no S1 (Tabela 3).

TABELA 3. Índice de velocidade de emergência (IVE) do jatobazeiro em Aquidauana - MS, 20092010. Emergence speed index (ESI) of the jatoba in Aquidauana - MS, 2009-2010.

\begin{tabular}{cll}
\hline \multirow{2}{*}{ Substratos } & \multicolumn{2}{c}{ Ambientes } \\
\cline { 2 - 3 } $100 \%$ de solo (S1) & Estufa & Telado \\
\hline 90\% de solo e 10\% de composto orgânico (S2) & $1,02 \mathrm{Aa}^{*}$ & $0,89 \mathrm{Ab}$ \\
$80 \%$ de solo e 20\% de composto orgânico (S3) & $0,88 \mathrm{Ba}$ & $0,73 \mathrm{Cb}$ \\
$70 \%$ de solo e 30\% de composto orgânico (S4) & $0,84 \mathrm{Ba}$ & $0,74 \mathrm{Ca}$ \\
$60 \%$ de solo e 40\% de composto orgânico (S5) & $0,80 \mathrm{BCa}$ & $0,85 \mathrm{Aba}$ \\
$50 \%$ de solo e 50\% de composto orgânico (S6) & $0,72 \mathrm{Ca}$ & $0,78 \mathrm{BCa}$ \\
$40 \%$ de solo e 60\% de composto orgânico (S7) & $0,80 \mathrm{BCa}$ & $0,70 \mathrm{Ca}$ \\
$30 \%$ de solo e 70\% de composto orgânico (S8) & $0,80 \mathrm{BCa}$ & $0,70 \mathrm{Ca}$ \\
$20 \%$ de solo e 80\% de composto orgânico (S9) & $0,81 \mathrm{BCa}$ & $0.74 \mathrm{Ca}$ \\
$10 \%$ de solo e 90\% de composto orgânico (S10) & $0,88 \mathrm{Ba}$ & $0,75 \mathrm{BCa}$ \\
100\% de composto orgânico (S11) & $0,89 \mathrm{Ba}$ & $0,73 \mathrm{Cb}$ \\
\hline
\end{tabular}

*Letras iguais maiúsculas nas colunas e minúsculas nas linhas não diferem entre si, pelo teste de Tukey, a 5\% de probabilidade.

Os substratos com 100\% de solo (S1), $90 \%$ de solo (S2), 10\% de solo (S10) e sem solo (S11) propiciaram maiores IVE, na estufa plástica. Para os demais substratos, os ambientes não diferiram com relação ao IVE (Tabela 3). Verifica-se que, no substrato onde as plântulas tiveram maior IVE, no S1, estas estavam sob a estufa agrícola (A1). Este ambiente, mesmo não apresentando grande diferença de temperatura em relação ao telado (Tabela 2) nos horários de coletas diurnos, mas em função do material de cobertura e da própria estrutura, armazenava mais energia térmica noturna, o que pode ter favorecido maior metabolismo e, consequentemente, acelerado a emergência das plântulas no substrato com menor pH (Tabela 1).

As alturas das plântulas de jatobazeiro, nos diferentes substratos sob a estufa agrícola (A1), foram bem definidas e distintas. As maiores alturas ocorreram no S1 (100\% de solo), com mudas próximas aos $36 \mathrm{~cm}$ aos 120 DAS, enquanto nos demais substratos as médias das alturas ficaram próxima de $20 \mathrm{~cm}$, com exceção para o $\mathrm{S} 6(50 \%$ de solo $+50 \%$ de composto orgânico), no qual as alturas foram inferiores a $15 \mathrm{~cm}$ (Figura 1). Assim como observado para o IVE, as maiores mudas foram verificadas em substrato mais ácido (Tabela 1), e por apresentar adaptabilidade a solos do Cerrado, característica intrínseca da espécie, teve melhor resposta de crescimento no substrato com $100 \%$ de solo. 
O maior coeficiente de determinação $(0,9765)$ observado na relação altura das plântulas e tempo explica o maior crescimento das mudas no S1, em relação aos demais substratos (Figura 1). Esse melhor padrão de mudas pode estar associado à menor quantidade de matéria orgânica (Tabela 1). A matéria orgânica adicionada ao solo, provavelmente, melhorou suas condições físicas, contudo o jatobazeiro é pouco exigente em nutrição (DUBOC et al., 1996) por ser uma planta do Cerrado, e a adição de composto orgânico ao solo elevou o $\mathrm{pH}$ e o aumento considerável da quantidade de nutrientes (Tabela 1). Esses fatores podem ter provocado efeito fitotóxico e/ou inibido a absorção de alguns nutrientes essenciais, prejudicando o crescimento das mudas nos substratos em que foi adicionado o composto.

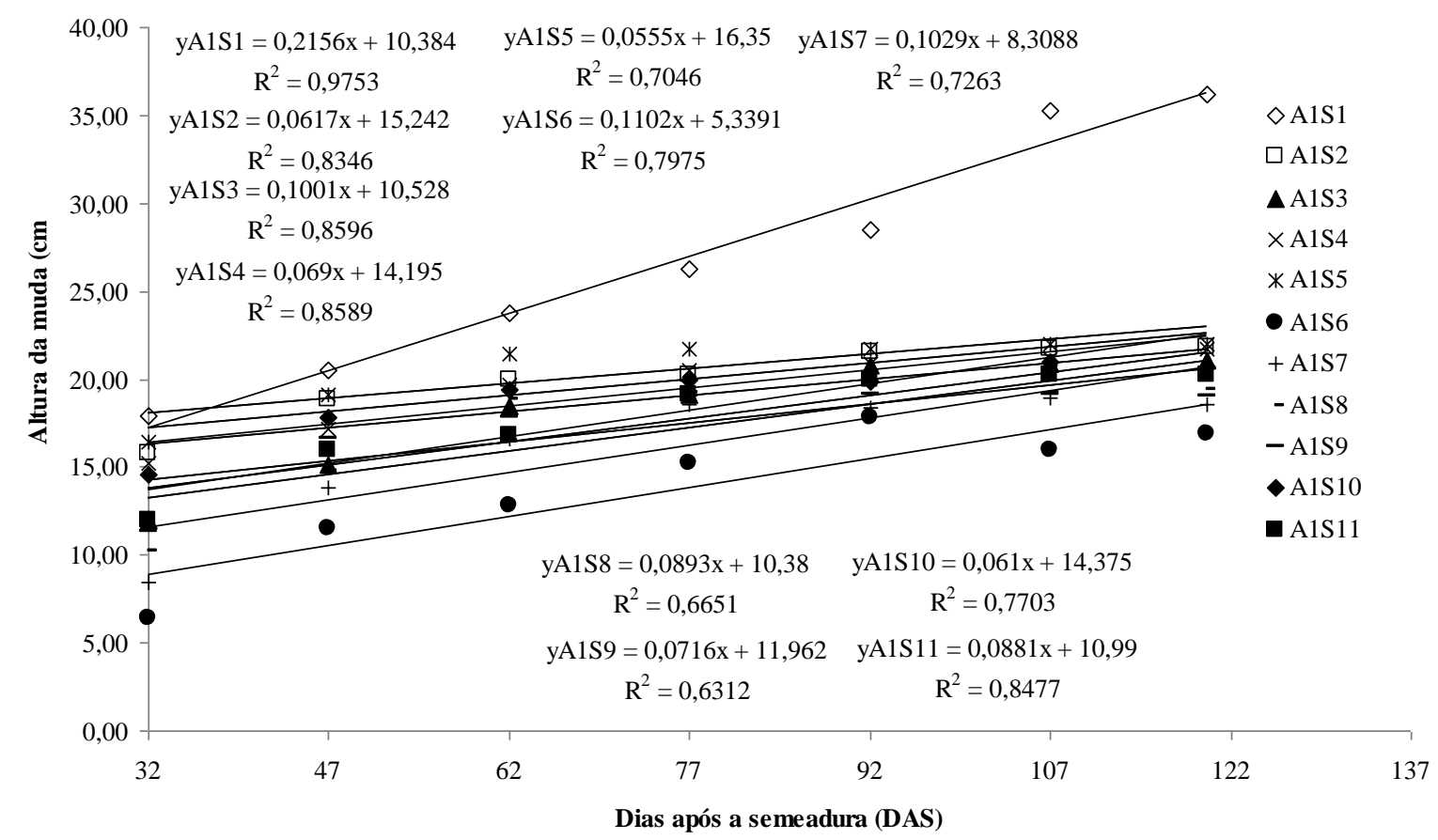

FIGURA1. Altura das plântulas de jatobá-do-cerrado nos diferentes substratos, na estufa agrícola (A1). Aquidauana - MS, 2009-2010. Jatobá do cerrado seedling height in different substrates in greenhouse (A1). Aquidauana - MS, 2009-2010.

SILVA et al. (2006) e ARAÚJO NETO et al. (2010) destacam que a matéria orgânica apresenta elevado poder de adsorção de água, obstrui os poros e prejudica o desenvolvimento radicular. Contudo, as mudas do jatobazeiro não responderam de forma positiva à adição de matéria orgânica aos substratos, por serem adaptadas a solos mais ácidos e com pouca retenção de água. Isto foi verificado nos substratos S6 (50\% de solo e 50\% de composto orgânico, S7 (40\% de solo e 60\% de composto orgânico) e S8 (30\% de solo e 70\% de composto orgânico), nos quais, provavelmente, houve menor percolação da água, que talvez dificultasse o desenvolvimento radicular, por falta de oxigenação das raízes, ocasionando menor crescimento das mudas do jatobá nestes substratos, comparados aos demais substratos (Figura 1). 


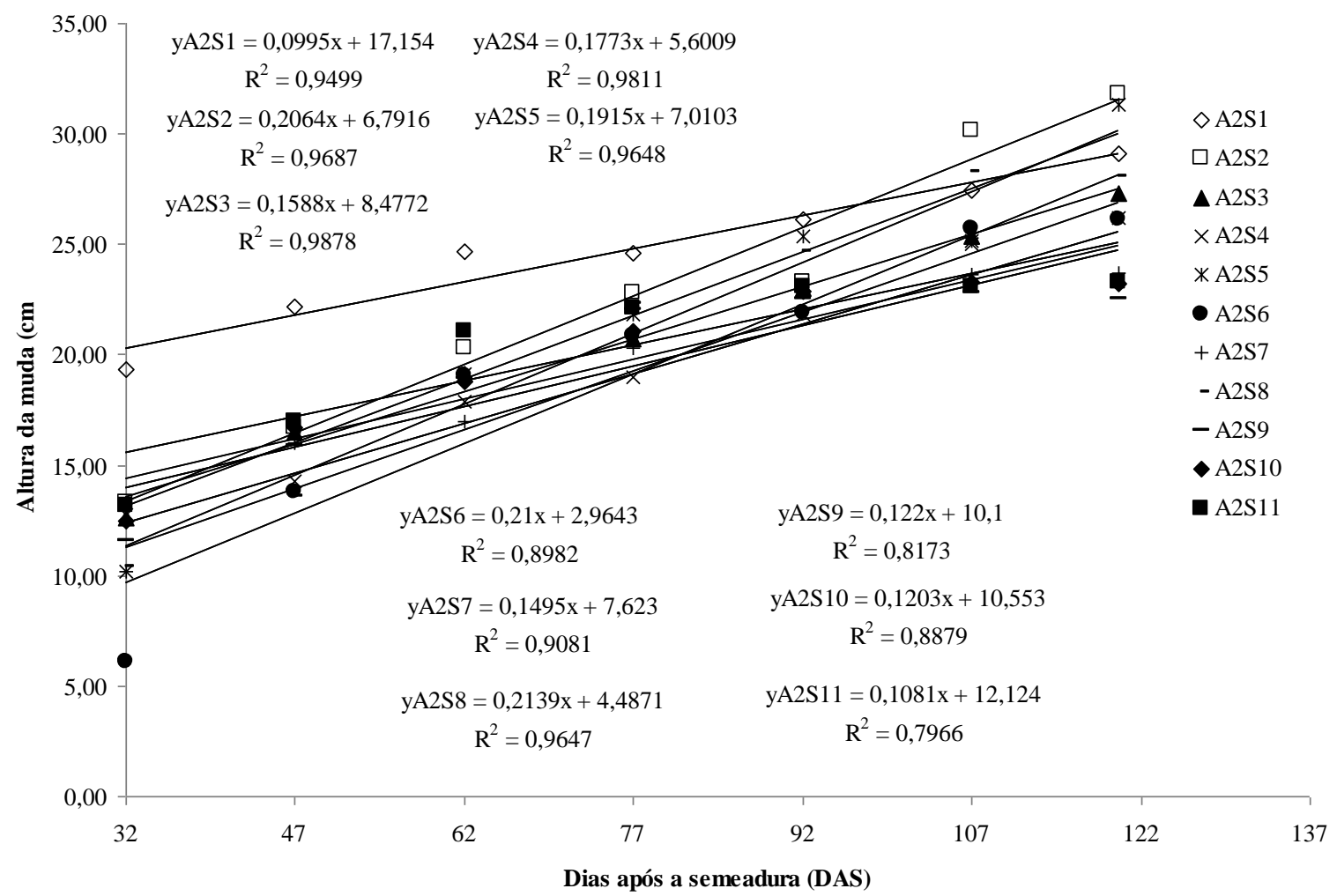

FIGURA 2. Altura das plântulas de jatobá-do-cerrado nos diferentes substratos, no telado de monofilamento (A2). Aquidauana - MS, 2009-2010. Jatobá do cerrado seedling height in different substrates in monofilament screen (A2). Aquidauana - MS, 2009-2010.

$\mathrm{O} \mathrm{pH}$ dos substratos foi fator determinante do desenvolvimento das mudas do jatobá-docerrado (Tabela 1). Por caracterizar-se uma região de solo ácido, as plantas nativas estão adaptadas a tal fator. A adição de matéria orgânica aos substratos elevou o $\mathrm{pH}$ e, provavelmente, inibiu o crescimento e o desenvolvimento das mudas. Talvez, a quantidade de alguns elementos químicos, contidos nos substratos com composto orgânico (Tabela 1), possa ter causado um desbalanceamento nutricional e efeito fitotóxico às mudas de jatobá, que possivelmente dificultou a absorção de elementos essenciais e reduziu o crescimento nesses substratos (Figuras 1 e 2).

Para a altura de plântulas de jatobá-do-cerrado no telado (A2), as plântulas do S1 (100\% de solo) tiveram crescimento inicial mais rápido em comparação aos dos demais substratos. No entanto, próximo ao dia 1-2-2010 (próximo dos 96 dias após a semeadura), a altura das mudas dos substratos S2 (90\% de solo e 10\% de composto orgânico), S5 (40\% de solo e 60\% de composto orgânico) e S11 (100\% decomposto orgânico) foi similar às alturas das mudas nesse substrato (Figura 2). Neste ambiente, a entrada de água pluvial pode ter auxiliado na decomposição de matéria orgânica e na lixiviação de nutrientes que poderiam ter causado toxidez às plântulas.

Os teores de Zn (zinco) e S (enxofre) aumentaram de forma exagerada com o aumento das porcentagens do composto. O S, por exemplo, passou de $4,20 \mathrm{mg} \mathrm{dm}^{-3}$ para $30,90 \mathrm{mg} \mathrm{dm}^{-3}$ do S1 para o S11. O mesmo ocorreu com o $\mathrm{Zn}$, que teve seus valores aumentados de $2,32 \mathrm{mg} \mathrm{dm}^{-3}$ para $26,19 \mathrm{mg} \mathrm{dm}^{-3}$ (Tabela 1). O Excesso de $\mathrm{Zn}$ foi fitotóxico às mudas, pois segundo DUBOC et al. (1996), que estudaram o estado nutricional do jatobá (Hymenaea courbaril L. var. stilbocarpa (Hayne), este elemento pode ser tóxico a mudas do courbaril, e o mesmo pode ter corrido com o stigonocarpa no presente trabalho.

O Ca (Cálcio) é um nutriente muito absorvido nos tecidos jovens e, no presente trabalho, verificou-se que seus teores estavam elevados (Tabela 1). $\mathrm{O} \mathrm{Ca}$ do substrato $\mathrm{S} 1$ foi de 2,52 Cmolc dm ${ }^{-3}$, contudo no substrato S11 (100\% de composto orgânico), foi de $14,87 \mathrm{Cmolc} \mathrm{dm}^{-3}$. 
O seu excesso nas plantas inibe a absorção de muitos nutrientes, principalmente do $\mathrm{Mg}$ (DUBOC et al., 1996). As plantas jovens possuem maior mobilidade dos nutrientes do que as plantas mais velhas, e as mudas do jatobazeiro demonstraram, em suas características morfológicas, que o excesso de nutrientes contido no composto orgânico dificultou o desenvolvimento das mudas.

O teste F para a massa seca da parte aérea (MSPA) e massa seca total da plântula (MST) não apontou diferenças significativas entre os ambientes de cultivo (A); porém, entre os substratos e suas interações com os ambientes, as diferenças foram altamente significativas. Para a altura de planta (AP), diâmetro de colo (DC), massa seca total da plântula (MST) e índice de qualidade de Dickson (IQD), houve diferenças significativas entre os ambientes, entre os substratos e suas interações (Tabela 4).

TABELA 4. Resumo da análise de variância (ANOVA). Aquidauana - MS, 2009-2010. Summary of the variance analysis (ANOVA). Aquidauana - MS, 2009-2010.

\begin{tabular}{ccccrrrr}
\hline & & \multicolumn{1}{c}{$\mathrm{AP}^{2}$} & DC & \multicolumn{1}{c}{ MSPA } & \multicolumn{1}{c}{ MSSR } & \multicolumn{1}{c}{ MST } & \multicolumn{1}{c}{ IQD } \\
\hline C.V. & GL & & \multicolumn{7}{c}{ Fcal } \\
A & 1 & $123,08^{* *}$ & $32,36^{* *}$ & $3,81^{\mathrm{NS}}$ & $11,56^{* *}$ & $0,23^{\mathrm{NS}}$ & $254,31^{* *}$ \\
$\mathrm{~S}$ & 10 & $61,61^{* *}$ & $16,90^{* *}$ & $80,05^{* *}$ & $562,09^{* *}$ & $335,31^{* *}$ & $153,90^{* *}$ \\
$\mathrm{~A} \mathrm{x} \mathrm{S}$ & 10 & $29,23^{* *}$ & $13,25^{* *}$ & $48,19^{* *}$ & $81,77^{* *}$ & $83,81^{* *}$ & $25,22^{* *}$ \\
\hline
\end{tabular}

${ }^{1}$ C.V. - causa de variação; GL - graus de liberdade; Fcalc - Fcalculado; A - ambientes; S - substratos; A x S - interação entre ambiente e substrato; ${ }^{N S}$ - não significativo; ** - significativo a 1\%. ${ }^{2}$ AP (altura de planta); DC (diâmetro de colo); MSPA (massa seca da parte aérea); MSSR (massa seca do sistema radicular); MST (massa seca total); IQD (índice de qualidade de Dickson).

As maiores alturas de mudas de jatobá (AP), na estufa plástica (A1), foram encontradas no substrato S1 (100\% de solo), com altura de $36,2 \mathrm{~cm}$, que pode ter refletido na variável índice de qualidade de Dickson (IQD), que foi de 2,18, o maior valor encontrado em todos os substratos avaliados (Tabela 5). Através destes dados de altura e das demais variáveis analisadas, foi possível verificar que o substrato com $100 \%$ de solo (S1) é um substrato adequado (REISSER JÚNIOR et al., 2008), refletindo em dados satisfatórios de produção e altura viável para as mudas irem para o campo (MELO \& MENDES, 2005). As doses dos nutrientes são importantes para um bom desenvolvimento das plântulas, pois o excesso ou a falta de algum nutriente pode causar um desequilíbrio na absorção nutricional. Desta forma, a adição deste composto orgânico comercial, independentemente da porcentagem, elevou o $\mathrm{pH}$ e pode ter causado um desbalanceamento nutricional e efeito fitotóxico às mudas do jatobá, prejudicando a absorção de certos nutrientes.

A partir do substrato $\mathrm{S} 2$, as mudas apresentaram maior altura no telado em comparação com a estufa (Tabela 5). A estrutura da tela, que permitia a entrada de água pluvial, auxiliou na lixiviação de elementos tóxicos e permitiu maior crescimento das mudas nestes substratos.

COSTA et al. (2010), produziram mudas de maracujazeiro em ambiente protegido e verificaram que os telados Sombrite ${ }^{\circledR}$ e Aluminet $^{\circledR}$, ambos com sombreamento de $50 \%$, promoveram maiores acúmulos de biomassa às mudas, comparada à estufa plástica, e observaram que o filme de polietileno da estufa agrícola produz um efeito estufa, o que auxilia no maior aquecimento interno. Este fator pode ter favorecido o desenvolvimento das mudas de jatobá neste ambiente, já que esta espécie está adaptada a locais de pleno sol (RAMOS et al., 2003).

No sombrite (A2), as maiores alturas ocorreram nos substratos S1, S2 e S5s não diferindo entre si. Verifica-se alta interação entre ambientes de cultivo e substratos no desenvolvimento das mudas do jatobazeiro. No substrato S1 (100\% de solo), as plantas da estufa estavam maiores que as do telado; já para os demais substratos, o melhor desenvolvimento foi registrado no sombrite (Tabela 5). Entretanto, para diâmetro do colo (DC), a maior altura das mudas no substrato com $100 \%$ de solo refletiu em maior desenvolvimento em diâmetro, que não diferiu das plantas dos substratos S5, S6, S7 e S8; contudo, nestes substratos, as plantas obtiveram um baixo desenvolvimento em altura. Esses dados mostram que o desenvolvimento das mudas de jatobá não deve ser avaliado com uma variável isolada (Tabela 5). 
TABELA 5. Interação entre ambientes e substratos (A x S) para a AP, DC e IQD. Aquidauana MS, 2009-2010. Interaction between environment and substrate (A x S) for AP, DC and IQD. Aquidauana - MS, 2009-2010.

\begin{tabular}{cllllll}
\hline & \multicolumn{2}{c}{ Altura de Planta $(\mathrm{cm})$} & \multicolumn{2}{c}{ Diâmetro do Colo $(\mathrm{mm})$} & \multicolumn{2}{c}{ Índice de Qualidade de Dickson } \\
\hline$* *$ & \multicolumn{1}{c}{ Estufa } & Telado & Estufa & Telado & Estufa & Telado \\
S1 & $36,2 \mathrm{Aa} *$ & $29,1 \mathrm{ABb}$ & $6,46 \mathrm{Aba}$ & $6,02 \mathrm{BCb}$ & $2,18 \mathrm{Aa}$ & $1,55 \mathrm{Ab}$ \\
S2 & $21,8 \mathrm{BCb}$ & $31,8 \mathrm{Aa}$ & $5,64 \mathrm{Ea}$ & $5,38 \mathrm{Ea}$ & $1,03 \mathrm{CDa}$ & $0,78 \mathrm{CDEb}$ \\
S3 & $21,1 \mathrm{BCDb}$ & $27,3 \mathrm{BCa}$ & $5,58 \mathrm{Ea}$ & $5,52 \mathrm{DEa}$ & $1,04 \mathrm{Ca}$ & $0,77 \mathrm{DEb}$ \\
S4 & $21,7 \mathrm{BCb}$ & $26,2 \mathrm{BCDa}$ & $5,92 \mathrm{CDEb}$ & $6,46 \mathrm{Aba}$ & $0,89 \mathrm{CDEFa}$ & $0,86 \mathrm{BCDa}$ \\
S5 & $22,0 \mathrm{Bb}$ & $31,3 \mathrm{Aa}$ & $6,28 \mathrm{ABCa}$ & $5,48 \mathrm{DEb}$ & $0,98 \mathrm{CDEa}$ & $0,90 \mathrm{BCDa}$ \\
S6 & $16,9 \mathrm{~Eb}$ & $26,1 \mathrm{CDEa}$ & $6,40 \mathrm{Aba}$ & $5,84 \mathrm{CDEb}$ & $0,87 \mathrm{DEFa}$ & $0,67 \mathrm{~Eb}$ \\
S7 & $18,6 \mathrm{DEb}$ & $23,7 \mathrm{DEFa}$ & $6,72 \mathrm{Aa}$ & $5,90 \mathrm{CDb}$ & $0,99 \mathrm{CDEa}$ & $0,80 \mathrm{CDEb}$ \\
S8 & $19,4 \mathrm{BCDEb}$ & $28,1 \mathrm{BCa}$ & $6,52 \mathrm{Aba}$ & $5,90 \mathrm{CDb}$ & $0,85 \mathrm{EFa}$ & $0,93 \mathrm{BCa}$ \\
S9 & $19,0 \mathrm{CDEb}$ & $22,5 \mathrm{Fa}$ & $5,78 \mathrm{DEb}$ & $6,52 \mathrm{Aa}$ & $0,79 \mathrm{Fb}$ & $1,02 \mathrm{Ba}$ \\
S10 & $20,7 \mathrm{BCDb}$ & $23,2 \mathrm{EFa}$ & $6,16 \mathrm{BCDa}$ & $6,12 \mathrm{ABCa}$ & $0,91 \mathrm{CDEFa}$ & $0,98 \mathrm{Ba}$ \\
S11 & $20,2 \mathrm{BCDb}$ & $23,3 \mathrm{DEFa}$ & $6,40 \mathrm{Aba}$ & $6,28 \mathrm{ABCa}$ & $1,31 \mathrm{Ba}$ & $0,93 \mathrm{BCb}$ \\
\hline
\end{tabular}

* Letras iguais maiúsculas nas colunas e minúsculas nas linhas não diferem entre si, pelo teste de Tukey, a 5\% de probabilidade. ** (S1) $100 \%$ de solo; (S2) 90\% de solo e 10\% de composto orgânico; (S3) 80\% de solo e 20\% de composto orgânico; (S4) 70\% de solo e 30\% de composto orgânico; (S5) 60\% de solo e 40\% de composto orgânico; (S6) 50\% de solo e 50\% de composto orgânico; (S7) 40\% de solo e 60\% de composto orgânico; (S8) 30\% de solo e 70\% de composto orgânico; (S9) $20 \%$ de solo e $80 \%$ de composto orgânico; (S10) 10\% de solo e 90\% de composto orgânico; (S11) 100\% de composto orgânico.

Conforme os dados da interação ambientes e substratos, foi possível verificar maior acúmulo de massa seca da parte aérea (MSPA) na estufa plástica, no substrato com 100\% de solo, o mesmo ocorrendo no sombrite; contudo o com 100\% de solo não diferiu do S8 (30\% de solo e $70 \%$ de composto orgânico). Na massa seca do sistema radicular (MSSR) e massa seca total da plântula (MST), nos dois ambientes de cultivo estudados, o substrato com $100 \%$ de solo foi onde ocorreu maior desenvolvimento das plântulas; para este substrato, a estufa plástica obteve 14,46 g de MST, mais que o dobro da massa dos demais substratos (Tabela 6). O que pode ter influenciado esta maior biomassa, foram um ambiente favorável e um substrato adequado, com aeração, níveis de matéria orgânica e também o pH, que estava em torno de 5,30 (Tabela 1), características de solos ácidos do Cerrado, que foram favoráveis ao desenvolvimento das mudas do jatobá.

TABELA 6. Interação entre ambientes e substratos (A x S) para a MSPA, MSSR e MST. Aquidauana - MS, 2009-2010. Interaction between environment and substrate (A x S) for MSPA, MSSR e MST. Aquidauana - MS, 2009-2010.

\begin{tabular}{|c|c|c|c|c|c|c|}
\hline \multirow[b]{2}{*}{$* *$} & \multicolumn{2}{|c|}{$\begin{array}{c}\text { Massa Seca da Parte } \\
\text { Aérea }(\mathrm{g})\end{array}$} & \multicolumn{2}{|c|}{$\begin{array}{c}\text { Massa Seca do Sistema } \\
\text { Radicular }(\mathrm{g})\end{array}$} & \multicolumn{2}{|c|}{$\begin{array}{c}\text { Massa Seca Total } \\
\text { (g) }\end{array}$} \\
\hline & Estufa & Telado & Estufa & Telado & Estufa & Telado \\
\hline S1 & $7,20 \mathrm{Aa}^{*}$ & $4,07 \mathrm{BCb}$ & $7,25 \mathrm{Aa}$ & $4,70 \mathrm{Ab}$ & $14,46 \mathrm{Aa}$ & $8,77 \mathrm{Ab}$ \\
\hline S2 & $2,81 \mathrm{CDb}$ & $4,77 \mathrm{Aa}$ & $2,36 \mathrm{Ba}$ & $1,85 \mathrm{CDEFb}$ & $5,17 \mathrm{BCDb}$ & $6,62 \mathrm{Ba}$ \\
\hline S3 & $2,89 \mathrm{CDb}$ & 3,60BCDEa & $2,31 \mathrm{Ba}$ & 1,77DEFb & $5,20 \mathrm{BCa}$ & $5,37 \mathrm{Ca}$ \\
\hline $\mathrm{S} 4$ & $3,10 \mathrm{CDa}$ & 3,49CDEa & $1,75 \mathrm{CDa}$ & $1,74 \mathrm{DEFa}$ & 4,86CDEFa & $5,24 \mathrm{Ca}$ \\
\hline S5 & $3,81 \mathrm{Ba}$ & 3,91BCDa & $1,77 \mathrm{Cb}$ & $2,64 \mathrm{Ba}$ & $5,59 \mathrm{BCb}$ & $6,55 \mathrm{Ba}$ \\
\hline S6 & $2,05 \mathrm{~Eb}$ & $2,59 \mathrm{Fa}$ & 1,49CDEa & $1,54 \mathrm{Fa}$ & $3,55 \mathrm{~Gb}$ & $4,13 \mathrm{Da}$ \\
\hline S7 & $2,73 \mathrm{Db}$ & 3,47CDEa & $1,72 \mathrm{CDa}$ & $1,57 \mathrm{EFa}$ & $4,45 \mathrm{DEFb}$ & $5,04 \mathrm{Ca}$ \\
\hline S8 & $2,83 \mathrm{CDb}$ & 4,21Aba & $1,42 \mathrm{DEb}$ & 2,04CDa & $4,25 \mathrm{FGb}$ & $6,25 \mathrm{Ba}$ \\
\hline S9 & 2,98CDa & $3,04 \mathrm{EFa}$ & $1,35 \mathrm{~Eb}$ & $2,12 \mathrm{Ca}$ & $4,34 \mathrm{EFb}$ & $5,16 \mathrm{Ca}$ \\
\hline S10 & $3,40 \mathrm{BCa}$ & 3,32DEa & 1,64CDEb & 2,05CDa & 5,03BCDEa & $5,37 \mathrm{Ca}$ \\
\hline S11 & $3,14 \mathrm{CDa}$ & $3,09 \mathrm{EFa}$ & $2,60 \mathrm{Ba}$ & $1,90 \mathrm{CDEb}$ & $5,74 \mathrm{Ba}$ & $4,99 \mathrm{Cb}$ \\
\hline
\end{tabular}

* Letras iguais maiúsculas nas colunas e minúsculas nas linhas não diferem entre si, pelo teste de Tukey, a 5\% de probabilidade. ** (S1) $100 \%$ de solo; (S2) 90\% de solo e 10\% de composto orgânico; (S3) 80\% de solo e 20\% de composto orgânico; (S4) 70\% de solo e 30\% de composto orgânico; (S5) 60\% de solo e 40\% de composto orgânico; (S6) 50\% de solo e 50\% de composto orgânico; (S7) 40\% de solo e 60\% de composto orgânico; (S8) 30\% de solo e 70\% de composto orgânico; (S9) 20\% de solo e 80\% de composto orgânico; (S10) 10\% de solo e 90\% de composto orgânico; (S11) 100\% de composto orgânico. 
RAMOS et al. (2003), estudando produção de mudas de jatobá-do-cerrado em diferentes condições de sombreamento: $0 \%$ (pleno sol) e casa de vegetação com cobertura lateral e superior de sombrite verde com 30; 70 e 90 de sombreamento, concluíram que a maior altura ocorreu com $90 \%$ de sombreamento; contudo, essa altura não foi convertida em massa seca de raiz, que foi maior no ambiente em pleno sol, verificando uma alocação de massa seca diferenciada, dependendo dos níveis de sombreamento, e menor adaptação da espécie em locais sombreados.

\section{CONCLUSÕES}

Em ambos os ambientes de cultivo, estufa e telado agrícola, as plantas emergiram mais rapidamente, com maior crescimento e acúmulo de biomassa, no substrato composto pelo Argissolo Vermelho-Amarelo puro (S1).

No substrato sem adição do composto orgânico (S1), as plântulas apresentaram maior vigor na estufa agrícola.

As mudas do jatobá-do-cerrado não apresentaram resposta positiva em relação ao aumento das doses do composto orgânico.

O composto orgânico utilizado aumentou o $\mathrm{pH}$ dos substratos, apresentou excesso de certos nutrientes e não contribuiu para um crescimento efetivo das mudas.

Para os substratos contendo 0;10; 90 e 100\% de composto orgânico, houve maior velocidade de emergência das plântulas na estufa agrícola.

\section{AGRADECIMENTOS}

À Pró-Reitoria de Pesquisa e Pós-Graduação (PROPP) e à CAPES - Coordenação de Aperfeiçoamento de Pessoal de Nível Superior, pela concessão da bolsa. À Universidade Estadual de Mato Grosso do Sul - Unidade Universitária de Aquidauana.

\section{REFERÊNCIAS}

ARAUJO NETO, S.E.; GALVÃO, R.O.; FERREIRA, R.L.F.; PARMEJIANI, R.S.; NEGREIROS, J.R.S. Plantio direto de cebolinha sobre cobertura vegetal com efeito residual da aplicação de composto orgânico. Ciência Rural, Santa Maria, v.40, n.5, p.1.206-1.209, 2010.

CARVALHO FILHO J.L.S.C.; ARRIGONI-BLANK M.F.; BLANK A.F.; RANGEL, M.S.A. Produção de mudas de jatobá (Hymenaea courbaril L.) em diferentes ambientes, recipientes e composições de substratos. Cerne, Lavras, v.9, n.1, p.109-118, 2003.

CARVALHO, P.E.R. Jatobá-do-Cerrado - Hymenaea stigonocarpa. Colombo: Embrapa Florestas, 2007. 8 p. (Circular Técnica, 133).

COSTA, E.; LEAL, P.A.M.; SANTOS, L.C.R.; VIEIRA, L.C.R. Ambientes de cultivo, recipientes e substratos na produção de biomassa foliar e radicular em mudas de maracujazeiro-amarelo em Aquidauana - MS. Ciência e Agrotecnologia, Lavras, v.34, n.2, p.461-467, mar./abr. 2010.

DICKSON, A.; LEAF, A.L.; HOSNER, J.F. Quality appraisal of white spruce and white pine seedling stock in nurseries. Forestry Chronicle, Ottawa, v.36, p.10-13, 1960.

DUBOC, E.; VENTURIN, N.; VALE, F.R.; DAVIDE, A.C. Nutrição do jatobá (Hymenae courbaril L. var. Stilbocarba (Haene) Lee et lang). Cerne, Lavras, v.2, n.1, p.138-152, 1996.

ESTAT. Sistema para análises estatísticas (v. 2.0). Jaboticabal: Departamento de Ciências Exatas, FCAV-UNESP, 1994.

FARIA, J.P.; SANO, S.M.; AGOSTINI-COSTA, T.S. Jatobá-do-Cerrado. In: Frutas nativas da região Centro-Oeste do Brasil. Brasília: Embrapa Recursos Genéticos e Biotecnologia, 2006.

Cap.11. p.173-186. 
LORENZI, H. Árvores brasileiras: manual de identificação e cultivo de plantas arbóreas nativas do Brasil. 3. ed. Nova Odessa: Instituto Plantarum, 2000. v.1, 352 p.

MATUDA, T.G.; MARIA NETTO, F. Caracterização química parcial da semente de jatobá-do-cerrado (Hymenaea stigonocarpa Mart.). Ciência e Tecnologia de Alimentos, Campinas, v.25, n.2, jun. 2005. Disponível em: <www.scielo.br/scielo.php>. Acesso: 13 fev. 2010.

MELO, M.G.G.; MENDES, A.M.S. Jatobá - Hymenaea courbaril L. Manaus: Redes de Sementes da Amazônia, 2005. (Informativo Técnico, 9)

MOREIRA, M.A.T.; PAIVA SOBRINHO, S.; SILVA, S.J.; SIQUEIRA, A.G. Superação da dormência em sementes de jatobá Hymenaea courbaril L. In: SEMINÁRIO DE INICIAÇÃO CIENTIFICA, 3., 2005, Anápolis. Anais... Goiânia: UEG, 2005.

RAMOS, K.M.O.; FELFILI, J.M.; SILVA, J.C.S.; FAGG, C.W.; FRANCO, A.C. Desenvolvimento inicial de Plântulas de Hymenaea stigonocarpa Mart. ex. Hayne, sob diferentes condições de sombreamento. Brasil Florestal, Brasília, v.22, n.22, p.37-42, 2003.

REISSER JUNIOR, C.; MEDEIROS, C.A.B.; RADIN, B. Produção de mudas em estufas plásticas. Pelotas: Embrapa Clima Temperado, 2008. 5 p. Disponível em:

<http://www.cpact.embrapa.br/imprensa/artigos/2008/artigo\%20Reisser_alface.pdf>. Acesso em: 23 jun. 2010.

SALAMONI, A.T. Obtenção, caracterização e efeitos de xiloglucanas e derivados, de sementes de jatobá na cultura de tecidos vegetais. 2004. 147 f. Tese (Doutorado em Agroindústria, Setor de Tecnologia) - Universidade Federal do Paraná, Curitiba, 2004.

SCREMIN-DIAS, E. (Org.). Produção de sementes de espécies florestais nativas. Campo GrandeMS: Universidade Federal de Mato Grosso do Sul, 2006. 43 p. (Série Rede de Sementes do Pantanal).

SILVA, A.J.N.; CABEDA, M.S.V.; CARVALHO, F.G. Matéria orgânica e propriedades físicas de um Argissolo Amarelo Coeso sob sistemas de manejo com cana-de-açúcar. Revista Brasileira de Engenharia Agrícola e Ambiental, Campina Grande, v.10, n.3, p.579-585, 2006.

VIEIRA, E.A.; OLIVEIRA, A.M.R. de; LAURA, V.A. Alocação de biomassa em plântulas do jatobá-do-cerrado (Hymenaea stigonocarpa Mart.) submetidas à competição. In: SIMPÓSIO NACIONAL CERRADO, 9., SIMPÓSIO INTERNACIONAL SAVANAS TROPICAIS, 2., 2008, Brasília. Anais... Brasília: UFMS, 2008.

ZANELLA, F.; SONCELA, R.; LIMA, A.L.S. Formação de mudas de maracujazeiro-"amarelo" com níveis de sombreamento em Ji-Paraná - RO. Ciência e Agrotecnologia, Lavras, v.30, n.5, p.880-884, 2006. 